\title{
O discurso literário e suas questões: Guimarães Rosa interroga a arte ficcional
}

Betina Ribeiro Rodrigues da Cunha ${ }^{\star}$ Eduardo Alves Rodrigues ${ }^{\star \star}$

\section{Resumo}

Este trabalho discute aspectos da constituição e dos efeitos do discurso literário sobre a literatura, a arte ficcional, dando visibilidade ao modo como o próprio artista, no caso, Guimarães Rosa, reflete sobre a literatura que inventa e o processo que a torna material e socialmente presentificada, procedimento que indicia o modo como esse autor interroga a própria arte. Esse procedimento, no caso de Guimarães Rosa, permite dizer que sua arte não corresponde jamais à expressão contida e ordenadora de uma realidade exterior, mas à expressão de uma interrogação da relação entre essa realidade e o sujeito no mundo. Essa discussão ganha corpo ao longo de um exercício analítico do conto "Pirlimpsiquice", integrante da obra Primeiras estórias.

Palavras-chave: Discurso literário. Guimarães Rosa. "Pirlimpsiquice". Arte ficcional.

\section{Discussão preliminar: a questão da arte (ficcional)}

"[...] a arte e o céu são assuntos muitos sérios, países de primeira necessidade"

(LIMA, 1997, p. 66).

Um desenho geométrico ou um entrelaçamento de linhas harmoniosamente organizadas permitem entrever, por meio de sua forma concreta material, mesmo sutilmente, que, ao se realizarem como figurativas, disponibilizam interpretações, sentidos, podendo ser

\footnotetext{
" Doutora em Letras pela USP (1996). Professora do Mestrado em Letras do Instituto de Letras e Linguística da Universidade Federal de Uberlândia.

** Doutorando em Linguística pelo Instituto de Estudos da Linguagem da Universidade Estadual de Campinas (Unicamp). Mestre em Linguística pelo ILEEL/UFU. Apoio Capes.
}

Data de submissão: fev. 2013 - Data de aceite: abr. 2013 http:// http://dx.doi.org/10.5335/rdes.v9i1.3543 
lidas de acordo com o horizonte simbólico - teórico - que se mobiliza para lhes sustentar filiações. Aquilo que um manual de álgebra pode configurar como a descrição de um teorema ou lei geométrica, em outra dimensão, a da estética, por exemplo, pode ser compreendido como manifestação artística, ou justamente como arte.

A identificação dessas produções simbólicas com esse ou aquele gênero artístico implica, por sua vez, o reconhecimento da constituição simbólica e social do homem, que lhe impõe a convivência com o mundo das "coisas" e com a necessidade de discerni-lo, noutra palavra, interpretá-lo. Essas coisas são cotidianamente exteriorizadas como efeito de sua relação com as diferentes formas de materialidades significativas, como as linguagens, a partir da experiência de partilhar com outros interpretações, representações de algo do real que passam a constituir e conformar o que ele reconhece imaginariamente como realidade.

Dessa forma, podemos pensar a arte, ao mesmo tempo, como forma e como gesto de interpretação. Ou seja, a arte pode ser compreendida, também, como representação de conhecimento(s), teorizações mais ou menos intuitivas, em que um dos objetivos é fazer expor e harmonizar aspectos talvez mais profundos, mais íntimos de uma realidade particular, fazer partilhar uma interpretação sensível - política e histórica - de algo da experiência de ser e estar no mundo e, nessa medida, dar a ver aspectos da relação indissociável constitutiva entre o interior e a exterioridade que impõe ao homem, sujeito em sua divisão político-simbólica, uma demanda permanente de interpretação: não há sentidos sem interpretação (ORLANDI, 2007). Com efeito, podemos dizer que a arte funciona socialmente como um dos modos de interpretar algo do real, portanto, um dos modos de constituição e conformação da realidade.

É socialmente, também, que a arte se faz discursivamente e circula em suas múltiplas formas e efeitos: "a interpretação está presente em toda e qualquer manifestação da linguagem" (ORLANDI, 2007b, p. 9). Além disso, a arte se faz discursivamente, a partir da materialidade significativa do silêncio, assim como pode ser censurada, proibida pelas diferentes formas de silenciamento. ${ }^{1}$

Com isso, queremos explicitar o fato de que é a partir das diferentes formas materiais significativas que a arte, em suas múltiplas possibilidades de textualização, dispõe, no cenário social, discursividades que significam experiências estéticas, isto é, modos específicos de interpretação da relação entre sujeito e mundo, em que lhe são atribuídos sentidos possíveis. Compreendida como resultado de uma experiência estética, a arte parece colocar em cena algo da singularidade do sujeito: algo que marca o - e dá visibilidade ao - modo particular com que ele se apropria de sensações, impressões, imagens etc. que, de uma 
forma ou de outra, significam essa relação, dada aí a mediação da linguagem ${ }^{2}$ permitindo certa materialização dessas formações impressivas imaginárias.

Do modo como a compreendemos, a arte corresponde a um momento decisivo de transformação de certa configuração de mundo, ponto de convergência de conhecimentos e de sentidos atualizados e organizados, não como mera função da realidade exterior, mas como resultado da instauração de uma suposta verdade a partir de uma experiência estética em que o confronto com o possível tende à aparente harmonização e à conciliação de tendências, ligadas ou justificadas por uma determinada conjuntura histórica, política e social, em que o sujeito é parte constitutiva.

Ao procurar compreender a dimensão estética, Perniola, por exemplo, faz discernir o conceito do que ele denomina estética cognitiva: "parte da estética do século XX que considera a arte como portadora de uma verdade e que, por isso, lhe atribui uma tarefa e um valor essencialmente gnoseológicos" (1998, p. 85). Trata-se, a nosso ver, de uma perspectiva idealista sobre a constituição do conhecimento e da compreensão da dimensão estética, que, para nós, não se reduz ao cognitivo/gnoseológico. A arte, de nossa perspectiva, não porta uma verdade; constrói uma entre outras possíveis, ou faz ver uma verdade relativamente a outras possíveis. Essa construção decorre de um processo que expõe, ao mesmo tempo, o modo como algo do real passa a fazer sentido para o sujeito e, nessa medida, expõe uma verdade para esse sujeito.

O conhecimento produzido em diferentes campos do saber permite-nos, hoje, vislumbrar um vasto e articulado panorama não só sobre a dimensão estética como também sobre outras dimensões a ela necessariamente relacionadas, como a social, a histórica etc., em que a arte pode ser compreendida em sua dimensão política e simbólica, portanto, como uma força social no confronto com outras na disputa por sentido(s). Essa força é constituída pelo trabalho simbólico da ideologia, impondo no lugar da dispersão (de sentidos e interpretações) uma determinada direção, isto é, um lugar de assentamento de evidências (que explicariam o que decorre da relação do sujeito com o mundo). Nessa perspectiva, a arte é uma prática social, um modo, portanto, de textualização do político.

Dessa maneira, podemos pensar a arte em sua dinâmica própria, constituída por diferentes processos criativos em sua opacidade, impondo-se ao artista, determinando-lhe o trabalho, demandando-lhe uma posição relativamente a sua suposta consciência racional, colocando em jogo valores simbólicos insistentemente atuantes e recorrentes. Nessa situação, podemos vislumbrar, a partir de um determinado objeto simbólico significado como arte, algo da experiência de vida do sujeito artista, pelo modo como aí se relacionam imagens, símbolos, referências, discursos etc. - numa palavra, 
sentidos - que constituem e significam seu percurso histórico enquanto sujeito no mundo. Estamos fazendo referência às condições de produção dos objetos simbólicos que circulam socialmente enquanto arte; as condições de produção que sustentam e projetam socialmente relações diversas entre imaginação e invenção, organizadas em um arranjo aparentemente "plausível", para fazer alusão ao modo como Guimarães Rosa parece compreender esse processo. Em entrevista a Ascendino Leite, conforme Lima (1997, p. 39), Rosa reflete sobre o que seria a função da literatura e o papel do artista na sociedade:

Deitar no chão e imaginar histórias, poemas, romances, botando todo mundo conhecido como personagens, misturando as melhores coisas vistas e ouvidas, numa combinação mais limpa e mais plausível, porque - como muita gente já compreendeu e já falou - a vida não passa de histórias mal arranjadas, de espetáculo fora de foco.

Na perspectiva de Rosa, parece-nos possível afirmar que a obra - literária, poética ou de ficção, sobremaneira a sua própria - é um acontecimento, em que certa realidade - e o que ele tende a estabilizar de regiões da memória ${ }^{3}$ - é retomada, revivida e reatualizada, desvelando-se à medida que se concretiza, interrogando-se ao presentificar-se ${ }^{4}$, não sendo jamais apenas a expressão contida e ordenadora de uma realidade exterior, mesmo que assim pretendessem os exegetas da estética realista(-idealista). Para Rosa, a obra literária parece ser o lugar em que a realidade - "a vida" - é interrogada em seu desarranjo, em seu desajuste; lugar em que, sob enfoque específico, a realidade é reorganizada e torna-se mais compreensível, nas suas palavras, "mais limpa e mais plausível". Talvez pudéssemos dizer, a partir do que afirmou Rosa na referida entrevista, que a arte seria mais um lugar em que a dispersão própria ao real ganhe certa conformação legível e inteligível: mais um lugar em que a realidade passa a fazer sentido.

Contudo, não podemos esquecer que um objeto simbólico, como uma obra literária, ao circular socialmente com o estatuto de arte, corresponde à manifestação de uma prática simbólica que instaura uma necessidade, a de ser notada, contemplada, reconhecida, experenciada, lida, até mesmo como modo de justificar sua produção e inserção no mundo. E, particularmente, no mundo da sensibilidade. Assim, a obra de arte existe na medida em que, por um lado, existe uma conjuntura sócio-histórica tal que sustenta sua produção e a resguarda, e, por outro lado, porque existe um contemplador - leitor - que a reconhece como tal, validando e valorizando a experiência decorrente do exercício criativo, por meio de seu gesto de leitura da obra. Em outras palavras, a experiência estética favorece uma dada conjuntura e propicia aí certas posições ao sujeito: aí configuram-se a função-autor e a função-leitor, ou seja, representações da existência daquele que "cria" uma obra de arte e daquele que a "contempla", "atribuindo"-lhe sentido. 
Entre a obra e aquele que a contempla $^{5}$, estabelecem-se relações mediadas por uma experiência da arte que implica certa reflexão e orientação, conforme sugere Picon (1969, p. 59-71). Guimarães Rosa, em entrevista a Günter Lorenz, ao falar sobre o ofício da literatura e a necessidade de escrever, confessa: "[...] quero escrever livros que depois de amanhã não deixem de ser legíveis. Por isso, acrescentei à síntese existente a minha própria síntese, isto é, incluí em minha linguagem muitos outros elementos, para ter ainda mais possibilidade de expressão" (cf. LORENZ, 1994, p. 45-46).

Nesse sentido, podemos pensar que à orientação e à reflexão sugeridas por Picon, conforme explicitamos acima, o sertanejo responde com um profundo desejo de permanência e labor que se revestem de um propósito maior, aquele da busca do essencial e inefável que caracterizam a espécie e a fabulação humanas, de modo a compartilhar com o outro - leitor e, ao mesmo tempo, objetivo primeiro deste partilhar generoso - as grandes imagens de imanência e significação que, ultrapassando uma possível fragilidade das construções imagísticas e metafóricas regidas pela palavra, passam a funcionar como alegorias e símbolos dessa síntese original, tão cara a Guimarães Rosa.

Lembramos, nesse momento, que, como sujeito contemporâneo, Rosa vivenciou paradoxos e complexas tensões. Abraçadas pela definição geral de modernidade, essas condições determinaram a constituição de pensamentos, sugeriram perspectivas, recriaram dogmas e reordenaram, enfim, gestos de interpretação da realidade, com os quais o escritor se identificou e pelos quais, em sua produção ficcional, representou uma atitude particular diante da vida, mesmo que essa atitude tenha sido expressa - como não poderia deixar de ser - com base em uma apreensão de algo do Real em si deformante.

Todavia, o sujeito não parece capaz de produzir a percepção ou a compreensão de si e do mundo por si só: ele necessita do olhar do outro, de sua escuta. $\mathrm{O}$ "eu" não se torna "eu" sem a ação e o jogo especular com o outro. Bakthin (2000), por exemplo, na tentativa de compreender esse jogo, ensina que a experiência artística - em especial, a literária, da qual ele se ocupa detidamente - apresenta um caráter essencialmente dialógico: nenhum acontecimento se desenvolve e se conclui por uma única consciência; toda palavra é orientada para um destinatário, cujo reconhecimento e interlocução contribuem para a formação de uma cultura, de possibilidades de vida. De nossa parte, diremos que todo acontecimento recorta e significa, histórica e politicamente, a realidade como efeito da relação necessária do sujeito com outros sujeitos. Assim, a realidade constitui-se discursivamente como efeito de sentido entre locutores. ${ }^{7}$ Abre-se aí um espaço de interlocução em que os sujeitos se olham, se escutam, se significam. 
Com efeito, podemos pensar com Perniola (1998) que a cultura parece comportar - ou configurar-se como - um "superdestinatário" (cf. PERNIOLA, 1998, p. 132-143), ou seja, podendo funcionar como um lugar de escuta que congrega diversas posições ideologicamente estabelecidas, e que pode ratificar o fato de que qualquer discursividade requer ser escutada (lida). Fazemos, contudo, a ressalva de que a noção de cultura parece estabilizar o movimento dinâmico de constituição das diferentes realidades sociais, o que, de fato, para nós, comporta o dissenso, a divergência, o movimento. Dessa forma, o que Guimarães Rosa afirma sobre a capacidade da obra literária de "limpar", isto é, harmonizar e organizar a vida é por nós compreendido como um dos efeitos possíveis que a obra literária pode produzir: o de escrever uma vida aparentemente mais plausível e mais limpa.

A experiência da arte, nessa perspectiva, não prescinde da partilha social em juízo, aspecto, aliás, de lúcidas análises feitas por Jauss (1979). O alemão confere grande importância à recepção da obra de arte, que, em sua opinião, não pode ser compreendida sem que se considere o efeito que produz(iu). A história da recepção torna-se, assim, parte essencial da própria obra, sobretudo porque, em certo sentido, é o reconhecimento por parte do destinatário ou do leitor que legitima e assegura seu caráter artístico. Ressaltamos, mais uma vez, dessa maneira, a importância das relações dialógicas para a consolidação de uma determinada produção artística, sobretudo em razão do lugar de interlocução que ela instaura e atualiza a cada gesto de leitura, em que os limites de sua textualidade abrem-se à medida que a obra se reportar a diferentes (e muitas vezes anônimos) interlocutores, espaços, dizeres, posições e "verdades"; enfim, ao se reportar a diferentes regiões da memória de dizeres, de discursos, enfim, de sentidos que constituem a história. ${ }^{8}$

Nesse momento, visamos a uma melhor delimitação deste tema tão amplo, o qual nos propomos a alinhavar neste artigo, com o objetivo de discuti-lo em face da obra literária de Guimarães Rosa em Primeiras estórias, mais detidamente em face de um dos contos que a integra, "Pirlimpisiquice". Ao mergulharmos nesse universo artístico repleto de especificidades discursivas resultantes de um momento estético próprio que faz ressoar e torna visível a genialidade do escritor, retomamos algumas questões e conceitos referentes à produção literária e seus instrumentos, sobretudo, para explicitar aspectos cruciais que marcam a singularidade da obra rosiana.

A partir do percurso teórico que aqui esboçamos, é forçoso reconhecer, inicialmente, por um lado, que as relações do homem consigo e com o outro são resolvidas nos meandros da formulação linguageira, sendo tomadas, portanto, como questões de natureza ao mesmo tempo simbólica, social, ideológica e política. Por outro lado, a formulação do 
discurso literário - diferentemente do discurso ordinário, muitas vezes visto pretensamente como objetivo e transparente, como instrumento a propiciar informação - admite uma regência outra que ultrapassa, assim como o discurso ordinário, cotidiano, a mera combinação de caracteres significativos autorizada por essa ou aquela lei; e, mesmo adequado ao cotidiano, o discurso literário possui uma especificidade sua no modo como dispõe em cena, com base em usos particulares da linguagem, discursos que o significam não como ordinário, mas como artístico.

O discurso literário é produzido a partir de uma série de outras premissas, em que a imaginação e a criatividade exercem função com forte dominância. Como resultado, isso abre espaço para a subversão da regência - sobredeterminação - que o meramente linguístico e/ou retórico produz sobre sua constituição e formulação. E, em muitos casos, o discurso literário pode se constituir como um lugar decisivo para a observação da incompletude e da opacidade da linguagem, da polissemia e de um tanto de brincadeiras com a materialidade significativa que a linguagem e a necessidade histórica do sentido permitem e instigam. Aí os procedimentos de análise do discurso literário podem perscrutar a palavra-imagem, sustentando os domínios de sua invenção e da polissemia de sua formulação.

E Guimarães Rosa, de forma literariamente astuta, foi capaz de construir, por meio de sua letra, enigmas, mistérios e experiências originais. Acrescentou à sua lavra elementos imaginativos, cifrados pela própria iniciação lúdica e crítica, o que parece ter-lhe permitido, em síntese, reunir, sob uma experiência com a e da palavra, uma categoria estético-literária moderna e inventiva, propiciando a instauração de um paradigma próprio de compreensão da textualidade poética e ficcional constitutiva da contemporaneidade.

A formulação inicial do conto "Pirlimpsiquice", que integra as Primeiras estórias, parece apontar essa direção. A estória inicia-se com a seguinte formulação: "aquilo na noite do nosso teatrinho foi de Oh" (ROSA, 2001, p. 86). A nosso ver, essa formulação inicial conforma 0 tom de mistério, ao mesmo tempo em que aguça o leitor a dar mais um passo no processo de reconstrução do enigma que sua escrita propõe: o de identificar mais um modo de interrogar a poluída e confusa realidade. Tal interrogação reescreve-se ao longo do conto mais de uma vez, como na fórmula-título, no que ela atualiza de magia e de sedução: pirlim-psi-quice. A magia e a sedução pela palavra, o clima de mistério e enigma que o conto parece propor mostrar encontram ancoragem na palavra habilmente trabalhada por Rosa, palavra que se desdobra e se transmuta ao longo do conto, como dissemos, mais de uma vez: como no par "aquilo-Oh" que integra sua formulação inicial aqui destacada.

Por um lado, a indeterminação do pronome - "aquilo" - funciona parafraseando a textualização do acontecimento- 
-estória que o narrador passa a contar e que coincide com o próprio texto do conto. Por outro lado, e concomitantemente, o pronome "aquilo" funciona parafraseando a metáfora do ponto de interrogação: aquilo o quê? - perguntamos imediatamente, dado, em especial, o efeito que a interjeição "oh" produz ao finalizar a formulação, como a insistir na permanência do enigma, do mistério, da interrogação e do que incitam: a produção de respostas. Outro efeito que a interjeição "oh" produz é o de, mais uma vez, estabelecer um lugar pela linguagem capaz de capturar o leitor e colocá-lo numa posição tal em que aceite o desafio de des-cobrir a aventura que ali se instaura.

Com efeito, essa interjeição "Oh" pelo modo como é trabalhada literariamente por Rosa, pelo modo como atualiza discursividades específicas - marca, de uma forma ou de outra, em suas inúmeras paráfrases, o tom da literatura rosiana: o de estabelecer uma arte interrogadora da vida, o que o leva, ao mesmo tempo e consequentemente, a interrogar a própria - inclusive a sua - arte.

\section{"Pirlimpsiquice" interrogando a arte ficcional}

Exemplo de um lugar decisivo para discutirmos o modo como Rosa estabelece um espaço de discussão e interrogação da (sua) arte ficcional é a instigante estória "Pirlimpsiquice" (ROSA, 2001, p. 86-96). Narrativa de uma estória dramatizada, seu arcabouço ficcional referenda, de uma forma quase mágica, o primado do que seria a metalinguagem sobre a pretensa clareza e racionalidade da língua.

De saída, o título do conto, por si só, convida a uma reflexão sobre a invenção e a opacidade da produção literária, na medida em que a palavra "pirlimpsiquice" constitui-se de um neologismo criado a partir da aglutinação de outras formas linguísticas: "pirlimpimpim", que é um pó mágico como aquele usado por Emília, Marquesa de Rabicó, personagem de Monteiro Lobato no Sítio do Picapau Amarelo; "psique", substantivo derivado do grego, que pode significar alma - em geral, compreendida como "princípio da vida, da sensibilidade e das atividades espirituais, enquanto constitui uma entidade ou uma substância" (cf. ABBAGNANO, 1962, p. 25). "Psique" pode definir, ainda, a consciência, o psiquismo do ser humano. O significado que esse termo tem na filosofia moderna e contemporânea, embora pressuponha genericamente uma acepção comum, é bastante complexo: "é o de uma relação da alma consigo mesma, de uma relação intrínseca ao homem, 'interior' ou 'espiritual', pela qual pode conhecer-se de modo imediato e privilegiado" (ABBAGNANO, 1962, p. 171). Essa dupla aglutinação ${ }^{9}$ permite-nos observar, mesmo intuitivamente, alguns elementos que permeiam a vivência do homem e sua representação no/do mundo sensível.

O "pó mágico", matéria fictícia, permite acessar o universo inventivo e impres- 
sivo que se localiza na "alma", na sensibilidade e na experiência de um exercício de busca de si próprio, que se daria por meio da consciência e da vontade de reconhecer-se como ser, como indivíduo. Ao explicitar a opacidade e a polissemia do título, estruturando um novo sentido e um novo paradigma de convivência com o texto, observamos que o leitor parece estar diante de uma senha, com a qual um contrato é firmado com Guimarães Rosa, $o$ autor, de forma a poder adentrar e continuar perseguindo o que poderia desfazer o mistério. O leitor, nessa perspectiva, estaria se apropriando da obra literária, em um processo mais íntimo de conivência, de compartilhamento da palavra e do processo de invenção. A palavra, no discurso literário, desliza e afasta-se de seu uso meramente pragmático e ordinário, passando a sustentar uma outra situação, em que o processo de significação conta mais que o sentido ou a coisa significada, materializando e fazendo ressoar outro objeto da linguagem: a imagem, a metáfora.

"Pirlimpsiquice" narra a estória ${ }^{10}$ de um grupo de alunos internos convidados a representar uma peça teatral dirigida pelo Dr. Perdigão, um professor de história e geografia que, medrosamente, passeia pelas artes, pelas frases de efeito e citações latinas, como a referendar sua sensibilidade e seu gosto artístico alicerçados no universo equilibrado dos modelos cristalizados e banalizados por um exercício estético e criativo envelhecido. ${ }^{11}$ Os "atores", um grupo selecionado de alunos pressionados pelos outros que não poderiam conhecer a peça de antemão, acabam por inventar uma "outra" estória, com o intuito de despistar o conhecimento da "verdadeira". Assim o narrador-personagem relata sua gênese:

Precisávamos de imaginar, depressa, alguma outra estória, mais inventada, que íamos falsamente contar, embaindo os demais no engano. [...]. Mas a outra estória, por nós tramada, prosseguia, aumentava, nunca terminava, com singulares-em-extraordinários episódios, que um outro vinha e propunha [...]. (ROSA, 2001, p. 88-89).

Trata-se de episódios tão ricos e criativos que, ainda segundo o narrador, "já, entre nós, era a 'nossa estória', que às vezes, chegávamos a preferir à outra, a 'estória de verdade', do drama" (ROSA, 2001, p. 89).

Paralelamente a essa "sobrepeça"12, convive uma outra, criada pelo aluno Gamboa e seu grupo, conta-nos o narrador: "de fato, circulava outra versão, completa, e por sinal bem aprontada, mas de todo mentirosa. Quem a espalhara? O Gamboa" (ROSA, 2001, p. 90). No momento crucial da apresentação, após diversas peripécias e contratempos envolvendo o grupo de alunos atores e o desempenho global da peça "original", essa estória acaba por fazer parte do texto que se encenava no palco.

Esse texto, com efeito, não é exatamente nenhum, mas todos, entrelaçados e recriados pelo grupo de atores, que se vê, repentinamente, despojado de um parâmetro inicial, dos limites concretos e específicos do texto "original" e dedi- 
cadamente ensaiado, cuja representação e encenação eram aguardadas pela plateia ali presente. Ao contar o ocorrido, o narrador afirma: "de repente, se viu: em parte, o que ele representava, era da estória do Gamboa!" (ROSA, 2001, p. 95); em seguida, acrescenta: "O pasmatório. Num instante, quente, tomei vergonha; acho que os outros também. Isso não podia, assim! Contracenamos. Começávamos, todos, de uma vez, a representar a nossa inventada estória. [...] A coisa que aconteceu no meio da hora. Foi no ímpeto da glória - foi - sem combinação" (ROSA, 2001, p. 95).

Entretanto, tal multiplicidade de textos resulta em uma verdadeira peça teatral, cujo sabor e vigor artísticos contribuem para o favorecimento do gozo da criação e da fruição do espetáculo: "[...] tudo tinha e tomava o forte, belo sentido, esse drama do agora, desconhecido, estúrdio, de todos o mais bonito, que nunca houve, ninguém escreveu, não se podendo representar outra vez e nunca mais" (ROSA, 2001, p. 95).

Finalmente, visto que cada um dos atores, nas palavras do narrador, "[...] se esquecera do seu mesmo, e estávamos transvivendo sobrecrentes, disto: que era o verdadeiro viver? E era bom demais, bonito - o milmaravilhoso - a gente voava, num amor, nas palavras: no que se ouvia dos outros e no nosso próprio falar" (ROSA, 2001, p. 96), ele próprio, narrador-personagem-ator, viu-se obrigado a dar término à peça - ao fio, ao rio, à roda, do representar sem fim (ROSA, 2001, p. 96) - abrupta- mente, conferindo-lhe o desfecho mais inusitado: "cheguei para frente, falando sempre, para a beira da beirada. Ainda olhei, antes. Tremeluzi. Dei a cambalhota. De propósito, me despenquei. E caí. E, me parece, o mundo se acabou" (ROSA, 2001, p. 96) ${ }^{13}$, materializando o corte súbito, porém necessário, entre duas realidades, extremamente distintas e concretas em suas "verdadeiras" existências.

A realidade e a realidade do encantamento, como sugerem as palavras do narrador em sua tentativa de compreender por que a encenação da peça, isto é, "aquilo nunca parava, não tinha nem começo nem fim? Não havia tempo decorrido. E como ajuizado terminar, então? Precisava. E fiz uma força, comigo, para me soltar do encantamento" (ROSA, 2001, p. 96).

Esse tema do caráter real e verdadeiro da obra de arte é lugar de inúmeras e diversas colocações e nuanças. Importa-nos, contudo, nesse momento, observar uma leitura que o conjunto da narrativa pode proporcionar. Esse resumo, mesmo recortado, deixa entrever a força da palavra recriada pela sensibilidade e pelo poder da criação artística.

Temos, na mesma narrativa, a convivência harmoniosa de cinco estórias: a estória do narrador, a estória a ser apresentada, aquela criada para despistar a que seria apresentada, aquela criada por Gamboa, e, finalmente, aquela que foi apresentada. O entrelaçamento e a convivência dessas estórias em "Pirlimpsiquice" põem em discussão a questão 
da verdade, da verossimilhança, da imitação criadora, da representação, da encenação, do papel da palavra-arte etc., enfim, da mímesis aristotélica - tema tão caro aos críticos e estudiosos da arte. Ao mesmo tempo, essas estórias ali identificáveis dão visibilidade a um processo de criação artístico calcado na disponibilidade para a magia, para o usufruto da emoção e para o exercício poderoso da inventividade, explorando a vocação à discursividade própria à palavra, que atualiza, ao ser formulada, um possível dinâmico para o sentido, colocando em questão a fixidez semântica dos significados, fazendo transpirar o movimento da significação pela instauração da metáfora como lugar, ao mesmo tempo, do possivel de ser algo e do possível de ser outra coisa.

O leitor, nesse processo, vê-se circunscrito à palavra, aliciado pela linguagem, que, reportando-se a uma determinada conjuntura sócio-histórica, torna-se condição essencial para possibilitar o exercício de uma subjetividade interpretativa, em tensão com a razão e com sua dimensão pragmática. Desse modo, podemos compreender o discurso literário - seja pela poesia, seja pela narrativa - como aquele que apresenta as características da materialização política e histórica da imagem - palavra-metáfora - e é, portanto, capaz de disponibilizar, pelo processo de significação, sensações, interpretações produzidas em razão da demanda decorrente da própria experiência de ser sujeito no mundo. $\mathrm{O}$ discurso literário, nessa perspectiva, é aquele, segundo nos ensina Lefebve (1980), capaz de poesia. Eis aí sua especificidade enquanto arte.

Seguindo esse raciocínio, podemos pensar a poesia como palavra-imagem-metáfora: esforço de presentificação de uma representação que pretende significar e, com isso, estabilizar uma determinada realidade. Podemos, assim, compreender a estória intitulada magicamente "Pirlimpsiquice" - e outras narrativas de Guimarães Rosa - como teia de reflexões constantes e dissonantes em suas possibilidades de existência, costurando soluções tensas que se desdobram em fortes interrogações que funcionam como gatilhos a estimular o adentramento na aventura de tentar compreender a vida, o homem e a arte, conclusão que, para nós, parece encontrar o que afirma Coutinho $^{14}$ a respeito da obra rosiana:

Obra eminentemente desconstrutora de toda visão monolítica do real, a narrativa de Guimarães Rosa se erige, desde Sagarana até seus póstumos Estas estórias e Ave, palavra!, como o espaço da indagação, da busca, onde, como afirma Riobaldo, em Grande sertão: veredas, referindo-se a si mesmo, não se tem certeza de coisa nenhuma, mas desconfia-se de muita coisa (COUTINHO, 2001, p. 37).

\section{Considerações finais}

Finalmente, e palmilhando os "descaminhos" do inconclusivo pensar e da contínua desconfiança, podemos compreender, em sua amplitude, a afirmativa que rege a epígrafe deste texto: a arte, assim como o céu, "são assuntos muito sérios", pois remetem à experiência de 
busca de compreensão para a condição humana no mundo, cujo sentido não está em lugar algum, mas se constitui de muitas maneiras em movimento permanente de transmutar-se noutro, em seu insistente e histórico devir. Arte e céu, cada um a sua maneira, constituem exercícios de representação de uma fluida, infinita e imaterial pluralidade, ou, em outros termos: "países de primeira necessidade".

Ou, ainda, como nos ensina Dr. Perdigão, em "Pirlimpsiquice": "- 'Representar é aprender a viver além dos levianos sentimentos, na verdadeira dignidade" (ROSA, 2001, p. 89). Isso nos leva a pensar a arte (ficcional) pela metáfora presente na interrogação do personagem-narrador sobre o estabanado colega Zé Boné: "O segredo ia ele poder guardar?" (ROSA, 2001, p. 88). Do modo como compreendemos, tanto a arte quanto o céu dispõem astutamente um segredo que está sempre na iminência de ser desvendado, mas que, no entanto, sempre resiste: um modo de interrogar a existência que nos impede de compreendê-la em sua totalidade.

\section{The literary discourse and its questions: G. Rosa interrogates the art of fiction}

\section{Abstract}

This paper discusses a few aspects concerning the constitution of the literary discourse and its effects on literature or on the art of fiction. Thus, the text tries to give visibi- lity to the way the artist - in this case Guimarães Rosa - considers the work he invents and the process that makes it materially and socially existent. This procedure seems to show how this author interrogates his own work/art and it also allows the interpretation according to which Rosa's work does not ever correspond to a restrained or ordering expression of exterior reality, but to the expression of how he interrogates the relation between this reality and the man (subject) existing in the world. This discussion deepens as it draws an analytical exercise of the short story "Pirlimpsiquice" that integrates the collection Primeiras estórias.

Key-words: Literary discourse. Guimarães Rosa. "Pirlimpsiquice". Art of fiction.

\section{Notas de referência}

1 Há diferentes trabalhos que exploram a relação entre silêncio e significação. Recomendamos a leitura do trabalho fundador de Eni Orlandi em As formas do silêncio (2007).

2 Não são apenas as diferentes formas de linguagem que sustentam processos de significação. O silêncio, conforme nos ensina Orlandi (2007), também se constitui como materialidade significativa sobre a qual se produzem diferentes processos de significação.

3 Estamos aqui operando com o conceito de memória discursiva, segundo o qual são os sentidos que constituem o interdiscurso, como define Pêcheux (1995, 1990): a memória irrepresentável que se dobra sobre o dizer a todo e qualquer momento em que ele se produz, determinando o que pode e deve ser dito.

4 Lefebve (1980), em sua obra Estrutura do discurso da poesia e da narrativa, discorre, com bastante propriedade, acerca da questão do texto literário enquanto instauração de um sentido revisitado que se presentifica.

5 O gesto de contemplação é aqui correlacionado por nós ao gesto de leitura, de interpretação, leitura sendo aí compreendida em sentido amplo e forte. 
6 Dentre as inúmeras e relevantes obras desse teórico russo que discutem e formulam a questão do dialogismo, destacamos Estética da criação verbal (BAKHTIN, 2000), em que essa questão é tratada com profundidade.

7 Premissa fundamental da teoria do discurso, tal como estabelecida por Michel Pêcheux na França (cf. PÊCHEUX, 1990, 1995, 1997).

8 Lembramos aqui o que nos ensina Paul Henry sobre a constituição história do sentido: "não há 'fato' ou 'evento' histórico que não faça sentido, que não peça interpretação, que não reclame que lhe achemos causas e consequências. É nisso que consiste para nós a história, nesse fazer sentido, mesmo que possamos divergir sobre esse sentido em cada caso" (2003, p. 51$52)$.

9 Conforme Nilce Sant'Anna Martins, em O léxico de Guimarães Rosa, "o termo é uma criação do autor, possivelmente com parte do vocábulo "pirlimpimpim" mais o radical "psico" e o sufixo "-ice" (2001, p. 387). É um termo lúdico, que sugere fantasias, fenômenos psíquicos estranhos.

10 É importante destacar a insistência com que Guimarães Rosa usa, não só no título do volume em que "Pirmimpsiquice" se encontra, mas ao longo de toda a sua produção literária, o vocábulo "estória", contrastando com "história": "a estória não quer ser história. A estória, em rigor, deve ser contra a História", diz ele, em Tutaméia (ROSA, 1995, p. 519), como a sublinhar a supremacia da fabulação e da fantasia em relação àquilo que pudesse figurar como mero registro histórico, por exemplo.

11 A imagem dúbia do Dr. Perdigão faz lembrar um poema de Camões, no qual o ambíguo Perdigão - ave e poeta - simboliza um homem ambivalente, dividido entre o tradicionalismo da cantiga de amigo e a profundidade do conceptualismo emprestado de Petrarca e do Classicismo: "Perdigão que o pensamento / Subiu a um alto lugar / Perde a pena de voar / Ganha a pena do tormento / não tem no ar nem no vento / Asas com que se sustenta: / Não há mal que lhe não venha" (cf. MOISÉS, 1976).

12 Termo cunhado por Paulo Rónai em "Vastos espaços" (cf. RÓNAI, 2001, p. 23).

13 Araújo (1998, p. 96) compreende esse ato como um "excessus vitae".

14 cf. COUTINHO, E. F. Diadorim e a desconstrução do olhar dicotômico em Grande sertão: veredas. (cf. DUARTE, 2001, p. 37-49).

\section{Referências}

ABBAGNANO, N. Dicionário de filosofia. Trad. de Alfredo Bosi et al. 2. ed. São Paulo: Mestre Jou, 1962.

ARAÚJO, H. V. $O$ espelho: contribuições ao estudo de Guimarães Rosa. São Paulo: Mandarim, 1998.

BAKHTIN, M. Estética da criação verbal. Trad. de Paulo Bezerra. São Paulo: Martins Fontes, 1992.

COUTINHO, E. de F. Diadorim e a desconstrução do olhar dicotômico em Grande sertão: veredas. In: DUARTE, L. P.; ALVES, M. T. A. (Orgs.). Outras margens. Estudos da obra de Guimarães Rosa. Belo Horizonte: Autêntica, 2001. p. 37-49.

HENRY, Paul. A história não existe? In: ORLANDI, E. P. (Org.). Gestos de leitura: da história no discurso. Trad. de Bethania S. C. Mariani et al. 2. ed. Campinas, SP: Ed. da Unicamp, 1997. p. 29-53.

JAUSS, H. R. et al. A literatura e o leitor: textos de estética da recepção. Trad. de Luiz Costa Lima. Rio de Janeiro: Paz e Terra, 1979.

LEFEBVE, M.-J. Estrutura do discurso da poesia e da narrativa. Trad. de José Carlos S. Pereira. Coimbra: Livraria Almedina, 1980.

LIMA, Sônia M. Van Dijick. Ascendino Leite entrevista Guimarães Rosa. João Pessoa: Ed. da UFPB, 1997.

LORENZ, Günter. Diálogo com Guimarães Rosa. In: ROSA, J. G. Ficção completa. Rio de Janeiro: Nova Aguilar, 1995. v. 1. p. 25-61.

MARTINS, Nilce Sant'Anna. O léxico de Guimarães Rosa. 2. ed. São Paulo: EdUSP, 2001.

MOISÉS, M. A criação literária. São Paulo: EdUSP, 1976.

ORLANDI, Eni P. As formas do silêncio: no movimento dos sentidos. 6. ed. Campinas, SP: Ed. da Unicamp, 2007a. 
Interpretação; autoria, leitura e efeitos do trabalho simbólico. 5. ed. Campinas, SP: Pontes, 2007b.

PECHÊUX, M. Análise automática do discurso. In: GADET, F.; HAK, T. Por uma análise automática do discurso: uma introdução à obra de Michel Pêcheux. Trad. de Mariani, B. Campinas, SP: Ed. da Unicamp, 1990. p. 61-161.

. Semântica e discurso: uma crítica à afirmação do óbvio. Trad. de Eni Pulcinelli Orlandi. 2. ed. Campinas, SP: Ed. da Unicamp, 1995.

. O discurso: estrutura ou acontecimento. Trad. de Eni Pulcinelli Orlandi. 2. ed. Campinas: Pontes, 1997.

RÓNAI, Paulo. Vastos espaços. In: ROSA, J. G. Primeiras estórias. Rio de Janeiro: Nova Fronteira, 2001.

ROSA, J. G. Tutaméia. In: Ficção completa. Rio de Janeiro: Nova Aguilar, 1995. v. 1.

. Primeiras estórias. Rio de Janeiro:

Nova Fronteira, 2001. 